\title{
The self versus proxy report conundrum in juvenile idiopathic arthritis: implications for a cost-effectiveness analysis of integrated podiatry care
}

\author{
Gordon J Hendry ${ }^{1 *}$, Janet Gardner-Medwin ${ }^{3}$, Debbie E Turner², Jim Woodburn², Paula K Lorgelly ${ }^{4}$ \\ From Australasian Podiatry Council Conference 2011 \\ Melbourne, Australia. 26-29 April 2011
}

\section{Background}

JIA is associated with impaired health-related quality of life (HRQoL). Proxy reporting of health outcomes such as HRQoL is often required in the paediatric setting. However there is uncertainty regarding whether self- or proxy- reported HRQoL should be used in health economic analyses, as perceptions of well-being may differ between parent and child. The aim of this study was to estimate levels of agreement and association between self- and proxy-reported HRQoL in JIA.

\section{Methods}

The EQ5D is a generic measure of HRQoL commonly used in economic evaluations. It has 2 components; 1 ) EQ5D profile comprises of 5 domains; mobility, selfcare, usual activities, pain, and anxiety (scored as severe, moderate, or no problems); and 2) a $100 \mathrm{~mm}$ visual-analogue-scale (VAS). EQ5D profiles were used to calculate a weighted utility index (worst health=0.59 , best health $=1$ ) based on a tariff derived from a UK population sample. The EQ5D was self- and proxy-completed independently by JIA patient-parent/ guardian pairs in the paediatric rheumatology multidisciplinary foot clinic $(n=40)$. Agreement for the EQ5D profile items was estimated using Cohen's linear-weighted kappa $\left(\kappa_{\mathrm{w}}\right)(>0.4=$ moderate agreement $)$ and $95 \%$ confidence intervals. Agreement for the utility

\footnotetext{
* Correspondence: gordon.hendry@gcu.ac.uk

'School of Biomedical and Health Sciences, University of Western Sydney, Sydney, Locked Bag 1797, Australia

Full list of author information is available at the end of the article
}

index and VAS was estimated using the intraclass correlation coefficient (ICC) $(\geq 0.4-0.75=$ fair to good agreement) with 95\% confidence intervals. Consistency was estimated using Kendall's Tau $(\tau)$ and Pearson's correlation coefficient $(r) \quad(\geq 0.4-0.6=$ moderate-strong consistency).

\section{Results}

Self- versus proxy- agreement was moderate for selfcare $\left(\kappa_{\mathrm{w}}=0.44\right)$ and usual activities $\left(\kappa_{\mathrm{w}}=0.44\right)$, but less than moderate for mobility $\left(\kappa_{\mathrm{w}}=0.29\right)$, pain $\left(\kappa_{\mathrm{w}}=0.29\right)$, and anxiety $\left(\kappa_{\mathrm{w}}=0.20\right)$. There was good agreement for EQ5D VAS (ICC $=0.59)$, but poor agreement for the utility index $(\mathrm{ICC}=0.23)$. The consistency of HRQoL reporting was moderate for self-care $(\tau=0.47)$ and usual activities $(\tau=0.44)$, but weak for mobility $(\tau=0.31)$, pain $(\tau=0.33)$, and anxiety $(\tau=0.23)$. Consistency was good for EQ5D VAS $(\mathrm{r}=0.59)$ but weak for utility index $(\tau=0.28)$.

\section{Conclusions}

The levels of agreement and association between patients with JIA and parent-proxies are at best moderate for all EQ5D measures. This has important implications for cost-utility analyses using QALYs derived from the EQ5D utility index. Further research is required to determine feasibility of using self- and proxy reported outcomes in cost-effectiveness analyses of podiatric interventions.

\footnotetext{
Author details

${ }^{1}$ School of Biomedical and Health Sciences, University of Western Sydney, Sydney, Locked Bag 1797, Australia. ${ }^{2}$ Glasgow Caledonian University,
} 
Published: 20 May 2011

doi:10.1186/1757-1146-4-S1-P26

Cite this article as: Hendry et al.: The self versus proxy report

conundrum in juvenile idiopathic arthritis: implications for a cost-

effectiveness analysis of integrated podiatry care. Journal of Foot and

Ankle Research 2011 4(Suppl 1):P26.

Submit your next manuscript to BioMed Central and take full advantage of:

- Convenient online submission

- Thorough peer review

- No space constraints or color figure charges

- Immediate publication on acceptance

- Inclusion in PubMed, CAS, Scopus and Google Scholar

- Research which is freely available for redistribution

Submit your manuscript at www.biomedcentral.com/submit
C) Biomed Central 